\title{
Synthesis of Tobermorite Structure with Non-traditional Silica Components
}

\author{
Vit Cerny ${ }^{\#}$, Jan Fleischhacker", Magdalena Kocianova ${ }^{\#}$, Rostislav Drochytka ${ }^{\#}$

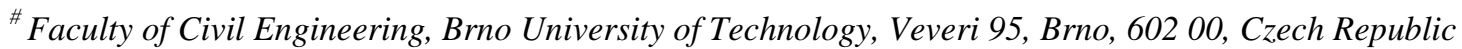 \\ E-mail: cerny.v@fce.vutbr.cz, fleischhacker.j@fce.vutbr.cz,kocianova.m@fce.vutbr.cz,drochytka.r@fce.vutbr.cz
}

\begin{abstract}
The main aim of the article is research of kinetics of creation of calcium silicate hydrate (CSH) and calcium aluminate hydrate $(\mathrm{CAH})$ phases in the autoclaved aerated concrete in dependence on type of raw materials. Regarding materials, this will be unique combinations of lime with fly ash, quartz sand or silica fume. The aim will be to prove the influence of ratio of individual types of materials on the CSH phase to determine optimal combinations of raw materials. The research focuses first on detailed analysis of the used materials. Next focus is kinetics of the creation of microstructures of silicate phases under ideal conditions of small-sized autoclave reactors $\left(250 \mathrm{ml}, 190{ }^{\circ} \mathrm{C}, 1.3 \mathrm{MPa}\right)$. The produced samples are further analysed using of $\mathrm{x}$-ray diffraction (XRD) and scanning electron microscopy (SEM) for qualitative valuation of created microcrystalline phases. The results show that the most suitable non-traditional silica component is ash from coal combustion. The optimal combination of amorphous and crystalline silicon in combination with $\mathrm{Al}_{2} \mathrm{O}_{3}$ provided the highest proportion of synthesized tobermorite even in more economical autoclaving variants.
\end{abstract}

Keywords - autoclaved aerated concrete; tobermorite; calcium sulfate; fly ash; silica fume.

\section{INTRODUCTION}

The needs of the end user should be always considered in order to sustain the development of civil engineering production. Today's trend is to look at the price of a product first and only subsequently value its quality. It is therefore critical to find the ways to maintain the low price level of the product without compromising its technical properties. One of the ways to achieve this result is to use low-cost materials that are in general by-products of industrial production or waste products. Among such materials are, for example, ashes from coal burning that takes place at high-temperature or through the fluid method. The production of autoclaved aerated concrete (AAC) is one of the many civil engineering fields where these by-product materials can be used.

$\mathrm{AAC}$ is a lightweight construction material with excellent thermal and technical properties in relation to its strength, is excellently workable and economically feasible. It is a material with long tradition, beginning in 1924, yet its potential can still be used today. Pure materials, meaning lime and quartz sand, were used since the beginning of production. The current trend is to find way to replace these more expensive materials with cheaper alternatives. It must be mentioned that ash from the high-temperature coal burning (fly ash) is also regularly used in AAC production. Nowadays the production of this ash is being limited, increasing the demand and, as a result, increasing its price. To the contrary, the production of fluidized bed combustion ashes, which are the by-products of burning coal in heat-production plants and power plants, is increasing. These products have lower usability but they are suitable in terms of price and $\mathrm{CaO}$ content.

One of the most important mechanical properties of each material is strength. In case of AAC, the carrier of strength is the mineral tobermorite. This mineral forms through the reaction of silica oxides and calcium in hydrothermal conditions. It belongs to the group of calcium hydrosilicates, with the chemical formula $\mathrm{Ca}_{5} \mathrm{Si}_{6} \mathrm{O}_{16}(\mathrm{OH})_{2} \cdot 4 \mathrm{H}_{2} \mathrm{O}$. This paper further covers the selection of materials suitable for AAC design. The selection process emphasizes the use of economically more suitable silica materials, particularly coal burning ashes. Upon sustaining these conditions, it is possible to increase competitiveness at the market as well as profits.

\section{A. Tobermorite Formation}

The molar ratio of $\mathrm{CaO} / \mathrm{SiO}_{2}$ and the temperature of the hydrothermal processes are the key elements for the formation of tobermorite. Some initial phases may already occur due to atmospheric conditions, such as $\mathrm{CSH}$, as well as by the hydration of cement. These are phases similar to tobermorite in terms of their structure, however, their crystalline grid is not as perfectly developed. Tobermorite is formed at a certain temperature inside the autoclave and a specific molar ratio of components. However, tobermorite is only a transitional phase, because 
it further crystalizes into xonotlite, which is undesirable due to its lower strength. It is therefore important to set the autoclave timing in a way that maximizes the amount of tobermorite and minimizes the formation of xonotlite. Fig. 1 shows the formation areas of the calcium hydrosilicates depending on temperature and molar ratio [1].

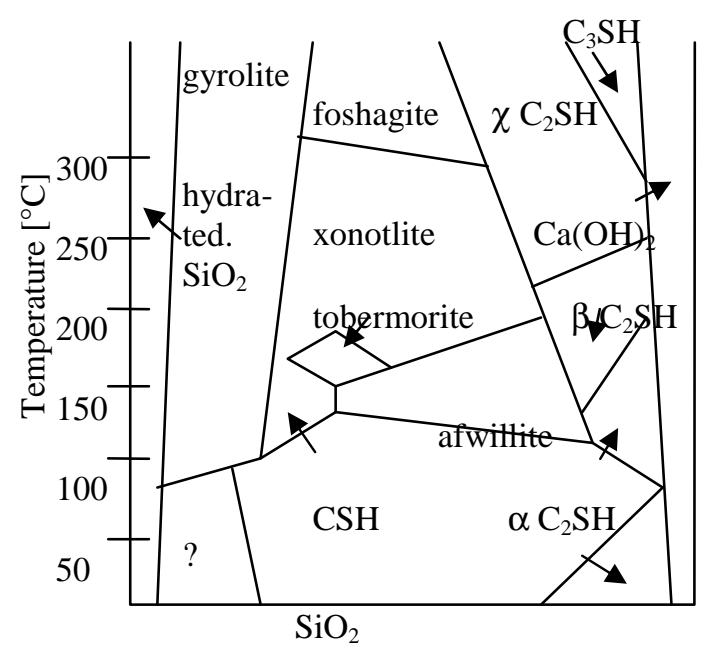

Fig. 1. Phase diagram $\mathrm{CaO}-\mathrm{SiO}_{2}-\mathrm{H}_{2} \mathrm{O}$ according to Bessey [1]

As it is apparent from the phase diagram, the mineral gyrolite might form in the case of C/S ratios lower than 0.5. Further, there is the desired mineral tobermorite with the ratio of $0.8-1.0$. Afwillite may form in the case of ratios exceeding 1.5. Hydrogarnets may also form within the system $\mathrm{CaO}-\mathrm{SiO}_{2}-\mathrm{Al}_{2} \mathrm{O}_{3}-\mathrm{H}_{2} \mathrm{O}$. The content of $\mathrm{Al}_{2} \mathrm{O}_{3}$ in the $\mathrm{CaO}-\mathrm{SiO}_{2}-$ the $\mathrm{H}_{2} \mathrm{O}$ system is critical to the formation of tobermorite. In the case of absence of $\mathrm{Al}_{2} \mathrm{O}_{3}$, tobermorite is formed from $\mathrm{CSH}$ gel, according to the equation 1 :

$$
\begin{aligned}
& \mathrm{CaO}+\mathrm{SiO}_{2}+\mathrm{H}_{2} \mathrm{O} \stackrel{c c a 1 h}{\longrightarrow} \mathrm{CSH}(\mathrm{II}) \stackrel{c c a 3 h}{\longrightarrow} \\
& \stackrel{c c a 3 h}{\longrightarrow} \mathrm{CSH}(\mathrm{I}) \stackrel{\text { cca } 4-5 h}{\longrightarrow} \text { tobermorite } \mathrm{C}_{5} \mathrm{~S}_{6} \mathrm{H}_{5}
\end{aligned}
$$

However, when $\mathrm{Al}_{2} \mathrm{O}_{3}$ is present, tobermorite forms within the $\mathrm{CaO}-\mathrm{SiO}_{2}-\mathrm{Al}_{2} \mathrm{O}_{3}-\mathrm{H}_{2} \mathrm{O}$ in two ways. (1) Tobermorite formation from the CSH phase: $\mathrm{CSH} \rightarrow$ tobermorite, (2) Tobermorite formation from katoite: $\mathrm{SiO}_{2}$, katoite, hydrogarnet, $\mathrm{CSH} \rightarrow \mathrm{Si}_{4}{ }^{+}, \mathrm{Ca}_{2}{ }^{+}, \mathrm{Al}_{3}{ }^{+}, \mathrm{OH}^{-}$. The first phase is a transformation within the solid state. The second is a transformation from a solid matter $\rightarrow$ solution, where tobermorite crystallizes from a solution. These processes take place at the same time [2].

\section{B. The Effect Of Silica Materials}

The first of the four crucial aspects affecting the formation of tobermorite is the character of the initial silica material. The main characteristics are their mineralogical character, amorphous or crystalline form of the material and specific surface area. The character of the silica material primarily affects the properties of the formed CSH gels (Fig. 2).

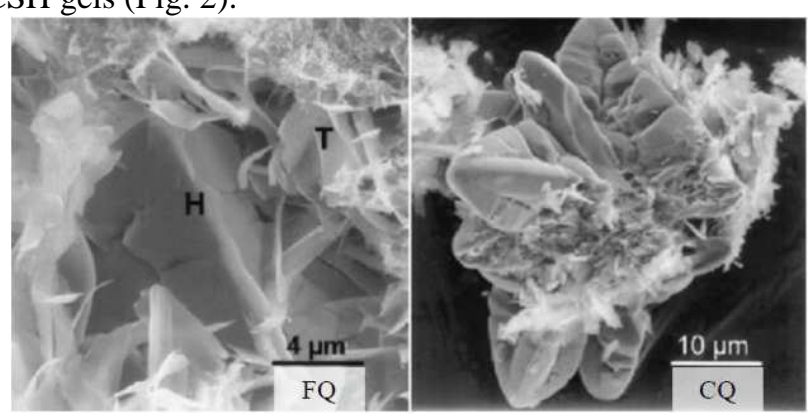

Fig. 2. Microscopic image of hydrographic decomposition by using fine FQ and coarse silicate CQ (H - hydrogenate, T - tobermorite) [3]

When using crystalline quartz, in the form of ground quartz sand, the gels form in the molecular $\mathrm{C} / \mathrm{S}$ ratio $\approx 1.69$, meaning they are calcium-rich. Shorter chains characterize these gels. On the contrary, when using amorphous quartz, the forming gels with a $\mathrm{C} / \mathrm{S} \approx 0.81$ ratio are silicon-rich and have long chains that less easily crystalize [4]. The result is a different rate of dissolving the silica material and therefore saturating the solution with these ions. Amorphous materials are more natural to dissolve, they saturate the solution with $\mathrm{Si}_{4}{ }^{+}$ions to a more considerable extent, and the CSH phases contain more of them. On the other hand, crystalline materials dissolve more slowly, a more considerable amount of the $\mathrm{Ca}_{2}{ }^{+}$ions are used for the formation of CSH phases, and these are therefore less branched and easier to crystallize into tobermorite [5].

The addition of amorphous silica in the form of ash can increase the rate of the tobermorite formation but, in the end, produces less of it. This way the ash decreases both the strength and the volumetric weight of the final product. [6, 7]. At the same time, the final product contains ash particles that failed to react, causing less connection between the crystals. This microstructure also results in increased absorbing power and shrinkage [8], [9]. Particle size affects the dissolving of silicon ions into the solution and therefore the formation of CSH phases (Fig. 3).

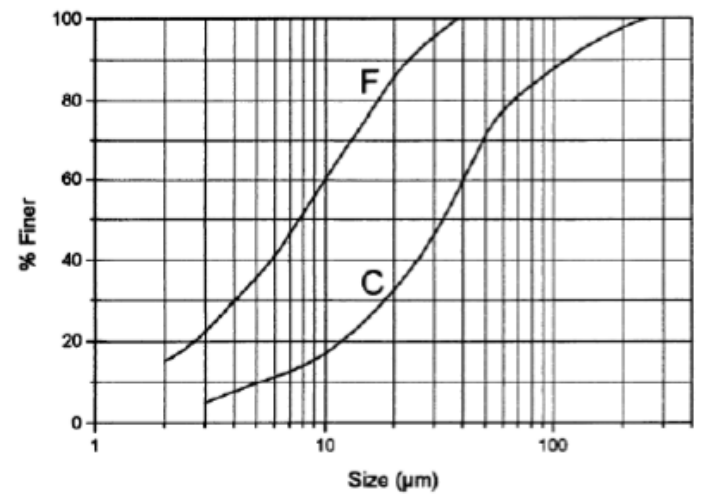

Fig. 3. Distribution of particles of siliceous materials ( $F$ - fine, $C$ - course) [3]

The saturation of the solution with silicon and calcium ions is closely related. Portlandite cannot be dissolved until the $\mathrm{Ca}_{2}{ }^{+}$ions are to a certain degree used up, for example by the formation of the CSH gel. The solubility of silica, and thus also of portlandite, decreases with the increased size 
of grain [10]. Particle size also has a particular effect within the hydrothermal conditions. The ability to decompose hydrogarnet (that crystallizes into tobermorite) decreases with the dropping specific surface area of silicates. As a result, the product, therefore, contains less of these phases [11], [3] However, quartz sand with a smaller specific surface area forms more crystalline tobermorite and can contain more massive quantities of it during more extended autoclave periods. The consequence could be a delayed transformation of tobermorite into xonotlite [12].

\section{The Effect of Hydrothermal Processes}

During hydrothermal synthesis, recrystallization occurs in the sense of Rabinder theory. The beginning of the crystallization is the end of the hydration of $\mathrm{CaO}$ and thus the formation of a spatial macrostructure from the $\mathrm{Ca}(\mathrm{OH})_{2}$ crystals. A continual transformation of crystalline phases takes place over the course of autoclaving, without achieving a balanced state. The specific surface area of crystals increases at the beginning of the hydrothermal synthesis, due to the crystallization of material and the creation of microstructure. In later stages, the phenomenon of the crystals growing larger and decreasing of their specific surface area takes place. This phenomenon can be observed after 20 hours of autoclaving [1].

The extension of the period of isothermal endurance causes an improvement of mechanical properties and mineralogical composition. More extended hydrothermal treatment enables better crystallization of tobermorite, when its crystals are larger and fit better together. This way they create a more homogenous microstructure, resulting in improvement of the mechanical properties of the AAC. Xonotlite may form upon the isothermal period of approximately 20 to 72 hours and sufficient supply of $\mathrm{CaO}$, which is however undesirable due to its lower mechanical strength in comparison to tobermorite [1].

If we increase the pressure autoclaving so it may cause the break of the crystals resulting in the opposite effect as prolonged isotherm. Therefore, it is necessary to find the optimal autoclave regime to achieve the best mineralogical composition and the resulting mechanical properties [13]. The temperature of the hydrothermal reaction mainly affects the rate of dissolution of the siliceous raw materials. At a temperature of $150{ }^{\circ} \mathrm{C}$ and 24 hours, $\mathrm{CSH}$ and $\mathrm{C}_{2} \mathrm{SH}$ with a higher $\mathrm{Ca}^{2+}$ content are formed. This reaction causes the slow dissolution of the quartz [14].

\section{MATERIAL AND METHOD}

\section{A. Testing Methodology}

The methodology of tests performed about this paper was divided into two parts. The first part regarded analysis of entry materials, where each raw material was subjected to chemical analysis (XRD - RTG diffraction analysis) to identify the number of oxides. The specific surface area was established using the permeable method according to Blaine and laser granulometry. Quicklime was selected as a basic raw material for increasing the content of calcium oxide in the mixture. Quartz sand (representing the crystalline type) and silica fume (representing the amorphous type) were selected for the experimental part as the main representatives of silica compounds with a high content of $\mathrm{SiO}_{2}$. Fly ash from coal burning was selected as the representative of byproduct materials.

The second part of the performed tests was focused on synthesizing tobermorite. A combination of quicklime and silica materials in the variable molar $\mathrm{C} / \mathrm{S}$ ratio of 0.73 and 1.00 was used for the synthesis. In the first phase, the materials were left to rest, causing the initial formation of the $\mathrm{CSH}$ products during this process. Subsequently, the samples $(20 \times 20 \times 100 \mathrm{~mm})$ were treated hydrothermally over the course of 4, 8 and 16 hours since the beginning of autoclaving in hydrothermal reactors (Teflon inner vessel, external stainless steel pressure vessel) with the volume of $250 \mathrm{ml}$ at $190^{\circ} \mathrm{C}$.

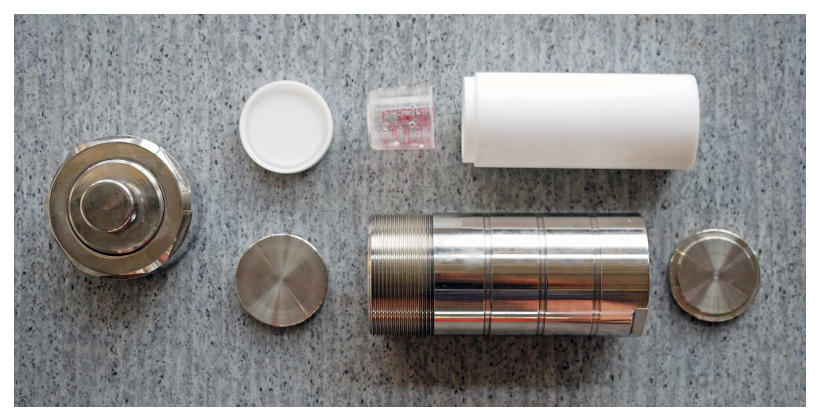

Fig. 4. Autoclave reactor $(250 \mathrm{ml})$

After autoclaving, the final product was dried at $60^{\circ} \mathrm{C}$ to constant weight. Next step was grinding of the test sample to the particle size lower than $0.063 \mathrm{~mm}$. Powdered sample was subjected to the X-ray diffraction analysis to determine the mineralogical composition. For the SEM analysis were used samples of size approx. $5 \times 5 \times 5 \mathrm{~mm}$. SEM at a magnification of 5000x and 1000x was used for qualitative valuation of created microcrystalline phases.

\section{B. Materials Used}

High-temperature fly ash, quicklime, quartz sand and silica fume were used for the experimental part. The properties of the individual materials can influence their behavior in the mix, together with other components, and determine the possibility of their use. For these reasons, it is necessary to carry out tests on input raw materials. In addition to mechanical properties, the addition of alternative raw materials (fly ash) can also influence the growth of mosses in building structures, for example. The use of fly ash in mixtures leads to environmental protection. For the fly ash process, the definition of $3 \mathrm{R}$ (Reuse, Recycle and Reduce) is sometimes used.

The input materials were subjected to chemical analysis. This analysis was necessary for the design of the formulae for the preparation of tobermorite. The individual percentage representation of the materials was tied to the molar $\mathrm{C} / \mathrm{S}$ ratio of the individual formulae. Table 1 shows the chemical composition and loss on ignition (LOI) of the entry materials with their respective amounts of oxides.

Particle density and specific surface area of the entry materials were also established (see Table 2). Specific surface area influences the solubility of materials and thus 
also the saturation of the solution with calcium and silicon ions. Specific surface area of materials was established using the Blaine's permeability method. Laser granulometry was used in order to establish the specific surface area of silica fume, where the surface is calculated as the sum of the surfaces of spherical particles.

TABLE I.

THE CHEMICAL COMPOSITION OF ENTRY MATERIALS

\begin{tabular}{|c|c|c|c|c|c|c|}
\hline Material & $\begin{array}{c}\text { Free } \\
\mathbf{C a O}\end{array}$ & $\begin{array}{c}\text { Tot. } \\
\mathbf{C a O}\end{array}$ & $\mathbf{S i O}_{2}$ & $\begin{array}{c}\mathbf{A l}_{2} \mathbf{O} \\
\mathbf{3}\end{array}$ & $\mathbf{S O}_{3}$ & LOI \\
\hline Fly ash & 0.05 & 3.44 & 58.80 & 19.70 & 0.18 & 1.43 \\
\hline Quicklime & 85.30 & 86.10 & 1.18 & 0.56 & 0.38 & 2.70 \\
\hline Quartz sand & 0.05 & 0.17 & 86.10 & 5.47 & 0.17 & 1.12 \\
\hline Silica fume & 0.12 & 0.40 & 93.20 & 0.23 & 0.29 & 2.69 \\
\hline
\end{tabular}

TABLE II.

PARTICLE DENSITY AND SURFACE OF ENTRY MATERIALS

\begin{tabular}{|c|c|c|}
\hline Material & $\begin{array}{c}\text { Particle Density } \\
{\left[\mathbf{g} \cdot \mathbf{c m}^{-3}\right]}\end{array}$ & $\begin{array}{c}\text { Spec. Surface } \\
\text { Area }\left[\mathbf{c m}^{\mathbf{2}} \cdot \mathbf{g}^{-1}\right]\end{array}$ \\
\hline Fly ash $^{1)}$ & 1.97 & $2,800^{1)}$ \\
\hline Quartz sand $^{1)}$ & 2.72 & $3,500^{1)}$ \\
\hline Silica fume & \\
\hline Quicklime & $15,200^{2)}$ \\
\hline $\begin{array}{l}\text { Methods of stimulation of the specific surface area: } \\
\text { 1) } \text { Blaine's permeability method, }\end{array}{ }^{2)}$ Laser granulometry. \\
\hline
\end{tabular}

\section{RESULTS AND DISCUSSION}

The experimental part was focused on observation of the effects influencing the formation of tobermorite. The formation of tobermorite phases in the $\mathrm{C}-\mathrm{A}-\mathrm{S}-\mathrm{H}$ system depends on the molar ratio of $\mathrm{CaO} / \mathrm{SiO}_{2}$. Molar ratios of $\mathrm{C} / \mathrm{S}=0.73$ and 1.00 with higher content of calcium oxide were selected to evaluate the effect of the ratio. Formulae for the preparation of tobermorite from the selected silica compounds and additives were designed by the established amount of oxides for the given molar ratios. Fly ash, quartz sand, and silica fume were selected as the silica compounds. Table 3 below shows the composition of the material mixtures, calculated by the chemical analysis of these materials and molar ratios.

XRD analyses were performed for all proposed formulae. Fig. 5-10 show an example of roentgenograms and Tables 46 show the results of mineralogical analyses of the samples by the individual silica materials.

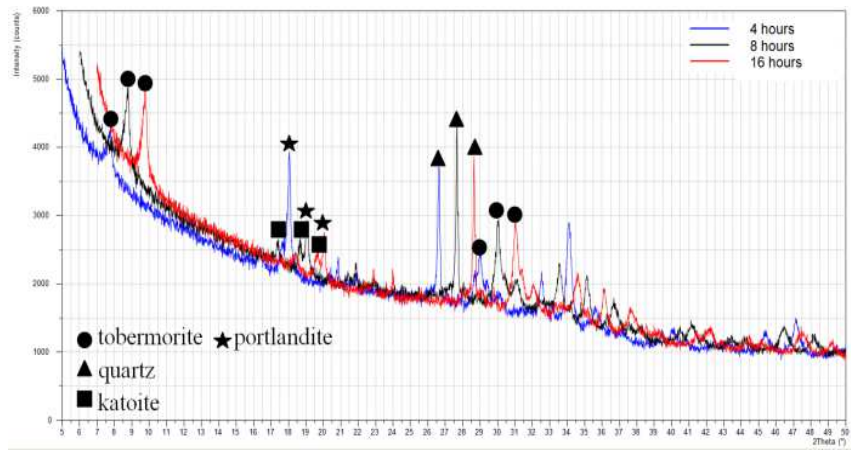

Fig. 5. Combination of roentgenograms of a sample using fly ash autoclaved at the temperature of $190{ }^{\circ} \mathrm{C}$ with a molar ratio of $\mathrm{C} / \mathrm{S}=0.73$

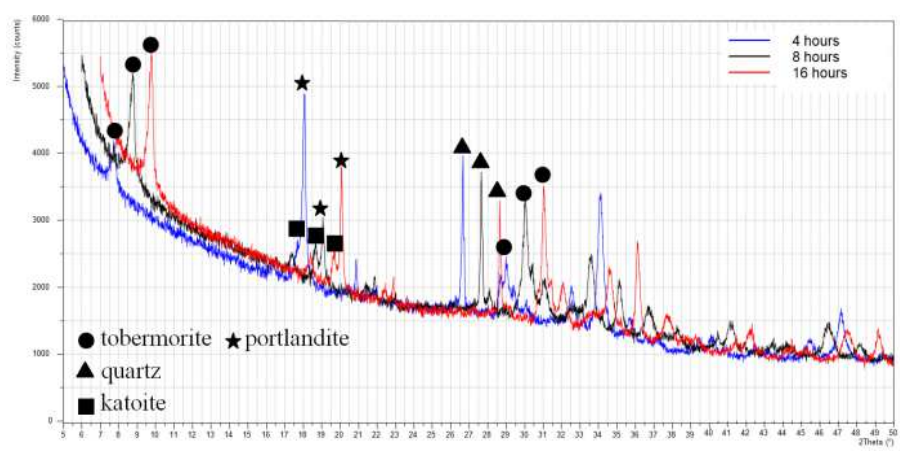

Fig. 6. Combination of roentgenograms of a sample using fly ash autoclaved at the temperature of $190{ }^{\circ} \mathrm{C}$ with a molar ratio of $\mathrm{C} / \mathrm{S}=1.00$

TABLE III.

FORMULAE FOR THE PREPARATION OF TOBERMORITE WITHOUT ADDITIVES

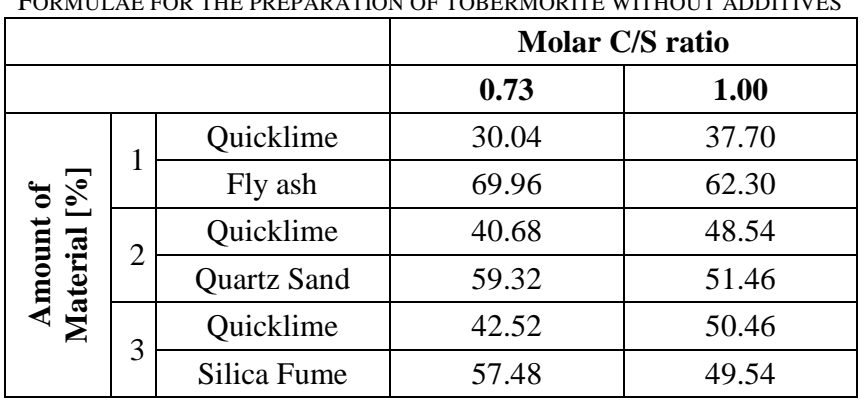

TABLE IV.

MINERALOGICAL COMPOSITION OF SAMPLES BY FLY ASH

\begin{tabular}{|c|c|c|c|c|c|c|}
\hline & \multicolumn{2}{|c|}{$\mathbf{4}$ hours } & $\mathbf{8}$ hours & \multicolumn{1}{|c|}{$\mathbf{~ h o u r s ~}$} \\
\hline C/S ratio & $\mathbf{0 . 7 3}$ & $\mathbf{1 . 0 0}$ & $\mathbf{0 . 7 3}$ & $\mathbf{1 . 0 0}$ & $\mathbf{0 . 7 3}$ & $\mathbf{1 . 0 0}$ \\
\hline Quartz & ++ & ++ & ++ & ++ & ++ & ++ \\
\hline Tobermorite & ++ & ++ & ++ & +++ & ++ & +++ \\
\hline Katoite & + & + & + & + & + & + \\
\hline Portlandite & ++ & +++ & + & ++ & + & ++ \\
\hline $\begin{array}{l}\text { Amorphous } \\
\text { phase }\end{array}$ & ++ & ++ & ++ & ++ & ++ & ++ \\
\hline $\begin{array}{l}\text { +++ the phase forms the majority part } \\
++ \text { the phase is present in a considerable amount } \\
+ \text { the phase is present in minor amount }\end{array}$ \\
\hline
\end{tabular}




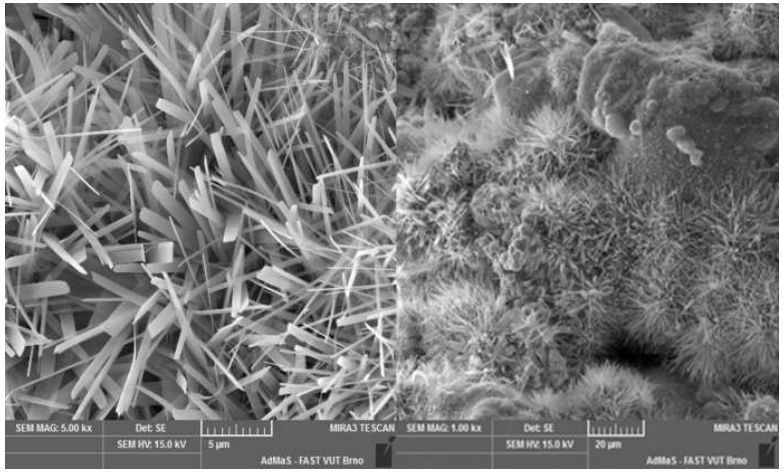

Fig. 7. SEM image of a sample created using fly ash without additives, autoclaved for 16 hours at the temperature of $190^{\circ} \mathrm{C}$.

Based on the evaluation of the roentgenograms (Fig. 5 and 6), we can generally conclude that the amount of tobermorite gradually increased with the duration of the hydrothermal synthesis, as well as that the amount of silica slightly decreased. The content of portlandite after 8 hours of autoclaving decreased rapidly. Katoite remained in the samples throughout the synthesis, and its content decreased slightly. The amount of tobermorite increased with the rising temperature and more extended autoclaving period, as well as with higher molar ratio $\mathrm{C} / \mathrm{S}$. The highest amount of tobermorite was observed in the mixture with the molar ratio of $\mathrm{C} / \mathrm{S}=1.00$ treated hydrothermally at the temperature of $190^{\circ} \mathrm{C}$ over the course of 8 hours.

Observation of the microstructure using an SEM (see Fig. 7) also reveals the high content of tobermorite phases. Small pointy crystals of tobermorite thickly cover the surface of the sample. Their length exceeds the width due to the content of aluminum that accelerates the crystallization of tobermorite.

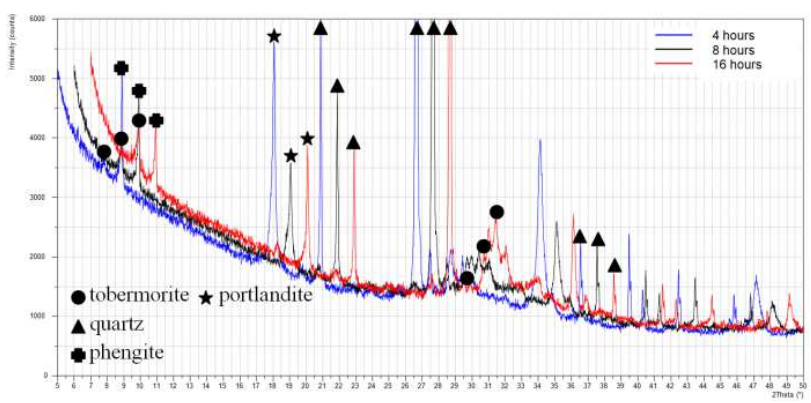

Fig. 8. Combination of roentgenograms of a sample using quartz sand autoclaved at the temperature of $190{ }^{\circ} \mathrm{C}$ with a molar ratio of $\mathrm{C} / \mathrm{S}=0.73$

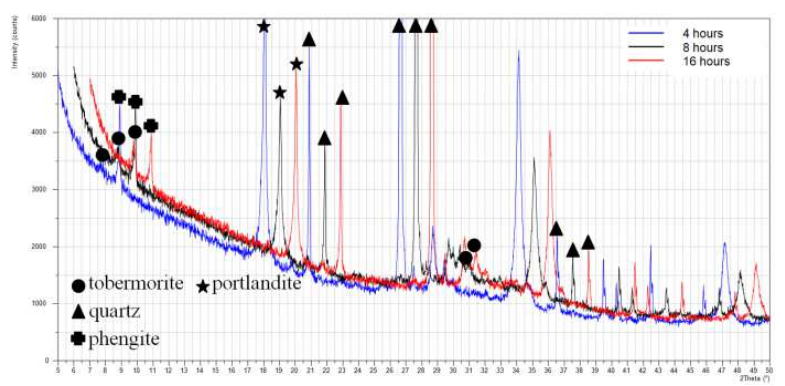

Fig. 9. Combination of roentgenograms of a sample using quartz sand autoclaved at the temperature of $190^{\circ} \mathrm{C}$ with a molar ratio of $\mathrm{C} / \mathrm{S}=1.00$
TABLE V.

MINERALOGICAL COMPOSITION OF SAMPLES BY QUARTZ SAND

\begin{tabular}{|c|c|c|c|c|c|c|}
\hline & \multicolumn{2}{|c|}{$\mathbf{4}$ hours } & \multicolumn{2}{c|}{$\mathbf{8}$ hours } & \multicolumn{2}{c|}{16 hours } \\
\hline C/S ratio & $\mathbf{0 . 7 3}$ & $\mathbf{1 . 0 0}$ & $\mathbf{0 . 7 3}$ & $\mathbf{1 . 0 0}$ & $\mathbf{0 . 7 3}$ & $\mathbf{1 . 0 0}$ \\
\hline Quartz & +++ & +++ & +++ & ++ & ++ & ++ \\
\hline Tobermorite & + & + & ++ & ++ & ++ & ++ \\
\hline Katoite & ++ & ++ & ++ & ++ & ++ & ++ \\
\hline Portlandite & +++ & +++ & ++ & ++ & ++ & ++ \\
\hline $\begin{array}{l}\text { Amorphous } \\
\text { phase }\end{array}$ & ++ & ++ & ++ & ++ & ++ & ++ \\
\hline \\
$\begin{array}{l}+++ \text { the phase forms the majority part } \\
++ \text { the phase is present in a considerable amount } \\
+ \text { the phase is present in a minor amount } \\
\text { the phase is not present }\end{array}$ \\
\hline
\end{tabular}

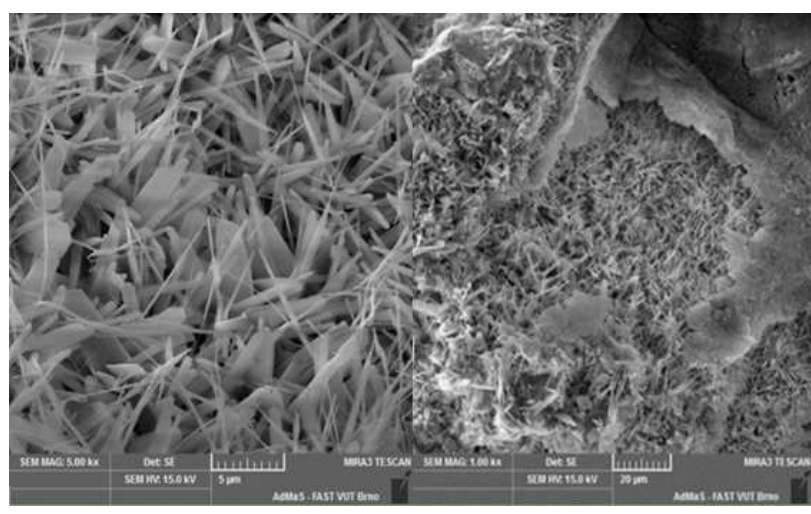

Fig. 10. SEM image of a sample created using quartz sand without additives, autoclaved for 16 hours at the temperature of $190{ }^{\circ} \mathrm{C}$.

Based on the roentgenograms (Fig. 8 and 9) we can conclude that the majority part of the mineralogical composition in the samples created using quartz sand at low molar C/S ratios and shorter autoclaving period forms the unreacted silica and portlandite, and in the lesser amount, they contain tobermorite and phengite. The presence of unused portlandite in the sample was caused by the low solubility of silica in the solution, thus having limited its ability to react with silica forming $\mathrm{CSH}$ phases. Samples also included phengite, a mineral contained in the used quartz sand. Tobermorite was formed after 8 hours of autoclaving, and its amount slightly increased with the course of the hydrothermal synthesis.

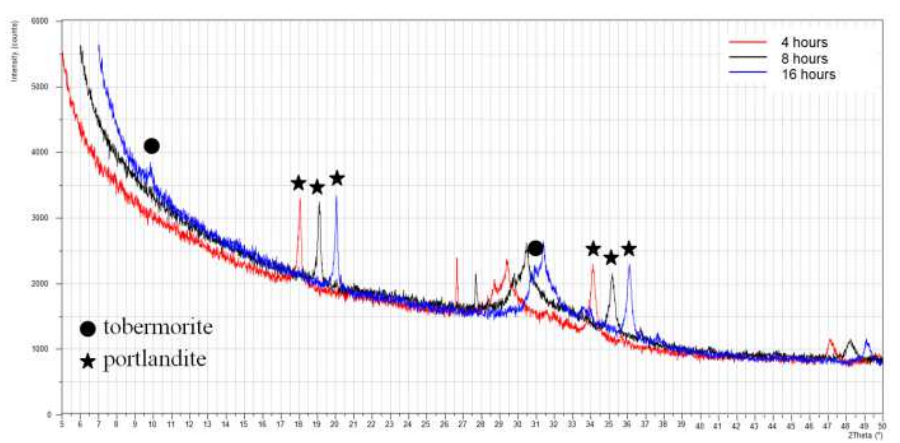

Fig. 11. Combination of roentgenograms of a sample using silica fume autoclaved at the temperature of $190{ }^{\circ} \mathrm{C}$ with a molar ratio of $\mathrm{C} / \mathrm{S}=0.73$ 


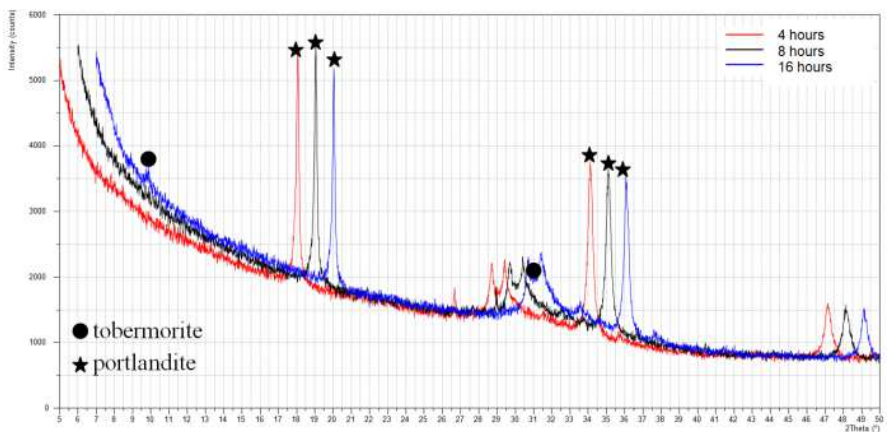

Fig. 12. Combination of roentgenograms of a sample using silica fume autoclaved at the temperature of $190{ }^{\circ} \mathrm{C}$ with a molar ratio of $\mathrm{C} / \mathrm{S}=1.00$

TABLE VI.

MineralogicAl COMPOSITION OF SAMPLES BY SILICA FUME

\begin{tabular}{|c|c|c|c|c|c|c|}
\hline & \multicolumn{2}{|c|}{$\mathbf{4}$ hours } & \multicolumn{2}{c|}{$\mathbf{8}$ hours } & \multicolumn{2}{c|}{$\mathbf{1 6}$ hours } \\
\hline C/S ratio & $\mathbf{0 . 7 3}$ & $\mathbf{1 . 0 0}$ & $\mathbf{0 . 7 3}$ & $\mathbf{1 . 0 0}$ & $\mathbf{0 . 7 3}$ & $\mathbf{1 . 0 0}$ \\
\hline Tobermorite & - & - & - & - & + & + \\
\hline Portlandite & ++ & +++ & ++ & +++ & ++ & +++ \\
\hline $\begin{array}{l}\text { Amorphous } \\
\text { phase }\end{array}$ & ++++ & ++++ & ++++ & ++++ & ++++ & ++++ \\
\hline $\begin{array}{l}\text { +++ the phase forms the majority part } \\
++ \text { the phase is present in a considerable amount } \\
+ \text { the phase is present in a minor amount } \\
\text { - the phase is not present }\end{array}$ & \\
\hline
\end{tabular}

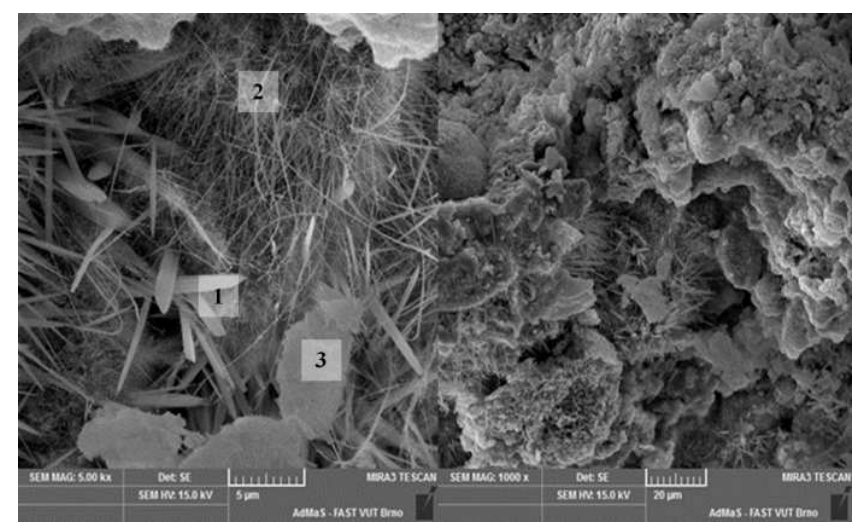

Fig. 13. SEM image of a sample created using silica fume without additives, autoclaved for 16 hours at the temperature of $190^{\circ} \mathrm{C}$. $(1-$ tobermorite, $2-$ CSH (I), 3 - CSH gel)

Based on the completed roentgenograms (Fig. 11 and 12) we can conclude that the majority of the mineralogical composition of the samples created using silica fume form amorphous phases of silicon dioxide, non-crystalized CSH phases, portlandite and trace amounts of tobermorite. The high amount of amorphous phases is likely the result of the high solubility of the silicate used. That produced $\mathrm{CSH}$ phases with low molar $\mathrm{C} / \mathrm{S}$ ratio, meaning with a high content of $\mathrm{SiO}_{2}$. These calcium hydrosilicates are less capable of crystallizing into tobermorite. Tobermorite was formed only after 16 hours of autoclaving and in trace amounts.

\section{CONCLUSION}

Using the analysis above, the effect of silicate species on tobermorite formation in the $\mathrm{C}-\mathrm{A}-\mathrm{S}-\mathrm{H}$ system was observed without the use of additives. Tobermorite was formed in highest amounts when using fly ash. The character of silicon dioxide and the content of aluminum oxide in the ash accelerated its crystallization, also confirmed by the presence of katoite. Tobermorite was formed in more significant amounts at higher molar $\mathrm{C} / \mathrm{S}$ ratio, due to the higher saturation of the environment with $\mathrm{Ca}_{2}{ }^{+}$ions. These were capable of reacting with the $\mathrm{Si}_{4}{ }^{+}$ions, creating CSH phases. The lower ratio caused oversaturation with silicon ions, creating high-silica CSH phases that are less capable of crystallizing into tobermorite.

The majority part of the sample's mineralogy created from quartz sand remained composed of mainly quartz and portlandite. The cause of the high amount of these minerals is the low solubility of quartz, resulting in the absence of $\mathrm{Si}_{4}{ }^{+}$ions necessary for the formation of $\mathrm{CSH}$ phases, in particular of tobermorite. Trace amounts of tobermorite were recorded at $190{ }^{\circ} \mathrm{C}$ and synthesis time of 16 hours. As a consequence is, that the sample contains a high amount of an amorphous phase mainly consisting of amorphous $\mathrm{SiO}_{2}$, $\mathrm{CSH}$ gel. The samples are containing silica fume as the silica compound was characterized by high content of amorphous phase and unreacted portlandite. The cause is the high solubility of amorphous silicate. Together with portlandite, this co-created high-silica $\mathrm{CSH}$ phases that barely crystalized further. The trace amount of tobermorite was recorded at the 16-hour synthesis period. Due to this, the sample contains a high amount of amorphous phase composed mostly of amorphous $\mathrm{SiO}_{2}$ and CSH gel.

\section{ACKNOWLEDGMENTS}

This paper has been worked out under the project No. LO1408 "AdMaS UP-Advanced Materials, Structures and Technologies," and under the project of the Grant Agency of the Czech Republic (registration number: No. 17-14198S). Kinetics of silicon micro-structure creation in dependence on hydrothermal conditions and type of used materials.

\section{REFERENCES}

[1] R. Drochytka, Pórobeton, 1st ed., Brno: Vutium, 1999, ISBN 80- 214-1476-6.

[2] K. Matsui, J. Kikua, M. Tsunashima, T. Ishikawa, S. Matsuno, A. Ogawa, M. Sato, "In situ time-resolved X-ray diffraction of tobermorite formation in autoclaved aerated concrete: Influence of silica source reactivity and $\mathrm{Al}$ addition," Cement and Concrete Research, vol.41, pp. 510-519, 2011.

[3] D.S. Klimesch, A. Ray, "Effects of quartz particle size and kaolin on hydrogarnet formation during autoclaving," Cement and Concrete Research, vol. 28, pp. 1317-1323, 1998.

[4] N.Y. Mostafa, S.A.S. El-Hemaly, E.I. Al-Wakeel, S.A. El-Korashy, P.W. Brown, "Activity of silica fume and de-aluminated kaolin at different temperatures," Cement and Concrete Research, vol. 31, pp. 905-911, 2001.

[5] R. Siauciunas, A. Baltusnikas, "Influence of $\mathrm{SiO}_{2}$ modification on hydrogarnets formation during hydrothermal synthesis," Cement and Concrete Research, vol. 33, pp. 1789-1793. 2003.

[6] Z. Jing, F. Jin, T. Hashida, N. Yamasaki, E.H. Ishida, "Influence of additions of coal fly ash and quartz on hydrothermal solidification of blast furnace slag," Cement and Concrete Research, vol. 38, pp. 976982, 2008. 
[7] H. Kurama, I.B. Topçu, C. Karakurt, "Properties of autoclaved aerated concrete produced from coal bottom ash," Journal of Materials Processing Technology, vol. 209, pp. 767-773, 2009.

[8] S. Goñi, A. Guerero, M.P. Luxán, A. Macías, "Activation of the fly ash pozzolanic reaction by hydrothermal conditions," Cement and Concrete Research, vol. 33, pp. 1399-1405,2003.

[9] N. Narayanan, K. Ramamurthy, "Microstructural investigation on aerated concrete," Cement and Concrete Research, vol. 30, pp. 457464, 2000.

[10] J. Kikuma, M. Tsunashima, T. Ishikawa, S. Matsuno, A. Ogawa, K. Matsui, M. Sato, "Effects of quartz particle size and water-to-solid ratio on hydrothermal synthesis of tobermorite studied by in-situ time-resolved X-ray diffraction," Journal of Solid State Chemistry, vol. 184, pp. 2066-2074, 2011.

[11] D.S. Klimesch, A. Ray, "Effects of quartz particle size on hydrogarnet formation during autoclaving at $180{ }^{\circ} \mathrm{C}$ in the $\mathrm{CaO}-$ $\mathrm{Al}_{2} \mathrm{O}_{3}-\mathrm{SiO}_{2}-\mathrm{H}_{2} \mathrm{O}$ system," Cement and Concrete Research, vol. 28, pp. 1309-1316, 1998.
[12] N. Isu, H. Ishida, T. Mitsuda, "Influence of quartz particle size on the chemical and mechanical properties of autoclaved aerated concrete (I) tobermorite formation," Cement and Concrete Research, vol. 25, pp. 243-248, 1995.

[13] E., Venhodová, "Development of tobermorite in aerated concrete depending on the length of autoclaving", $16^{\text {th }}$ International Conference of PhD Students, JUNIORSTAV: 4.1 Physical and chemical properties of building materials, Brno University of Technology, Faculty of Civil Engineering, p. 313, 2014, ISBN 97880-214-4851-3.

[14] K., Baltakys, R. Siauciunas, ,The influence of $\gamma-\mathrm{Al}_{2} \mathrm{O}_{3}$ and $\mathrm{Na}_{2} \mathrm{O}$ on the formation of calcium silicate hydrates in the $\mathrm{CaO}-$ quartz $-\mathrm{H}_{2} \mathrm{O}$ system“, Materials Science-Poland, vol. 25, No. 1, pp. 185-198, 2007. 